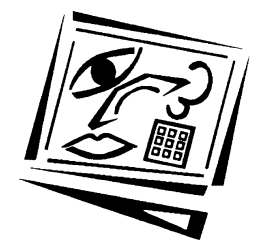

\title{
Is wiki an effective platform for group course work?
}

\author{
Irina Elgort, Alastair G Smith and Janet Toland \\ Victoria University of Wellington
}

\begin{abstract}
This study reports on students' and lecturers' perceptions of using wikis as a platform for conducting assessed group projects in two postgraduate Master's level university courses. The results highlight the fact that student attitudes to group work, in general, are mixed, and that the use of wikis per se is not enough to improve these attitudes. On the positive side, students found wikis useful for arranging information and sharing knowledge, while instructors thought wikis made managing and marking group work easier and more effective. Other issues related to using wikis as a collaborative learning tool in higher education are also considered.
\end{abstract}

\section{Introduction}

Since their widespread adoption at the turn of the millennium, wikis have been used as knowledge sharing and construction tools, with Wikipedia (2008) being a classic example of how information can be dynamically collected, verified and updated by a large number of individuals. Wikis are also used by organisations in the public and private sector for group project work and administration purposes. Recent publications suggest that wikis are gaining ground in higher education, as well (e.g. Augar, Raitman \& Zhou, 2004; Bower, Woo, Roberts \& Watters, 2006; Choy \& Ng, 2007).

However, not all use of wiki as a learning environment has been successful. Choy \& $\mathrm{Ng}$ (2007), for example, suggest that if a course does not require students to work collaboratively then the use of wikis may be problematic. Bower et al. (2006) also underscore the importance of the collaborative nature of the learning task and of task authenticity, as success factors in using wikis. Research that addresses pedagogical benefits and pitfalls of using wikis as a collaborative learning tool, however, is still rather limited, and the present project aims to further contribute to the body of evidence on using wikis in higher education.

\section{Background}

The present action research project was conducted in the context of a university pilot of a new suite of online student centred tools, the Learning Objects (LO) Campus Pack. The aim of the project was to investigate the use of wikis (implemented using the Teams LX extensions to the university's learning management system, Blackboard) as a support tool for working collaboratively on a group assignment in two postgraduate courses. Online teaching and learning systems and tools are no longer a novelty in the majority of New Zealand and Australian universities. In addition, both courses that took part in this pilot are offered by the School of Information Management, which has 
pioneered the local use of Blackboard and has been using other systems, such as WebCT, Chatterbox, Elluminate, to mention a few.

However, despite this reasonably extensive experience in using online tools to support courses, neither staff nor students have had much experience with using online tools that facilitate student centred learning as part of the course learning environment. In a Blackboard course website, for example, everything is set up by the course instructor, while students have very little or, more commonly, no control over the way their course websites are configured. This limitation may significantly skew both teacher and student perceptions and use of the online environment towards an instructionist, and away from a constructionist, approach to learning (Conole \& Dyke, 2004; Harel \& Papert, 1991; Duffy \& Jonassen, 1992). Introduction of wikis into the online learning environment, on the other hand, shifts the balance of control over the structure and content of a part of the virtual learning space to the student, and may significantly change the dynamics of online learning and collaboration, as well as students' perceptions of what online learning is about (Grierson et al., 2004).

The present action research project was initiated by the University Teaching Development Centre, which announced the introduction of blogging and wiki tools in an internal newsletter and asked for volunteers to take part in a pilot study. Four course coordinators attended the initial meeting, and two courses were selected as being suitable for the wiki pilot study. Both were Master's level courses and both had a substantial group work assignment which could translate well to a wiki environment. One of the courses, an information management course (it will be referred to as Course $A$ ), was a face to face course, and the other, a library studies course (it will be referred to as Course B), was offered in on campus and distance modes. This provided an opportunity to evaluate and compare the use of wiki in the context of face to face and distance learning.

The fact that both these courses were at a postgraduate level was a major factor in the instructors' decision to go ahead with the pilot. Postgraduate courses were perceived by the instructors as a lower risk environment for introducing wikis, compared to undergraduate courses for a number of reasons. Firstly, based on their prior experience, the instructors anticipated fewer issues around group assessment in general, because more mature postgraduate group members are more likely to "pull their weight". Furthermore, student numbers are generally lower in postgraduate courses, making it easier to introduce and manage teaching and learning innovation. Course teaching teams are smaller at the post graduate level, and communication among instructors is less of an issue. For example, both courses in the pilot had less than 30 students and were taught exclusively by one member of academic staff. This is not to say that the benefits of using wiki were necessarily considered to be larger for postgraduate compared to undergraduate courses. For example, the page history feature of the wiki environment that details individual student contributions was viewed as having high potential value in managing and facilitating group work at the undergraduate level. Trialling the use of wiki at the postgraduate level, therefore, was seen as a safe way of evaluating the technology before rolling it out to larger undergraduate courses.

The overarching question addressed in this study was whether wikis could facilitate collaborative learning and positively affect student attitudes to group work in the context of an assessed group project. More specifically, we were aiming to identify 
aspects of collaboration that would benefit from using wikis (e.g., collecting and organising information, knowledge creation and sharing, encouraging individual student involvement in the project).

\section{Collaboration as a learning technique in higher education}

The consensus in today's literature on higher education is that there is a role for cooperative and collaborative learning at both undergraduate and postgraduate levels. According to Barkley, Cross and Major (2005), for example, research findings demonstrate that collaboration promotes and improves learning (see also Millis \& Cottell, 1998), and is an important factor in academic achievement, personal development and student satisfaction. Encouraging active learning, and cooperation and collaboration among students are also among the seminal Seven Principles for Good Practice in Undergraduate Education (Chickering \& Gamson, 1987).

Collaboration is also an important life skill. The process of generating knowledge always has a social component (Fuchs-Kittowski \& Kohler, 2002). It is now widely recognised that the majority of innovations in organisations come about as a result of collaboration between groups. Hargadon (2003) makes the point that successful inventors are technology brokers who innovate by finding connections between people, ideas and objects. Because of this social component a tool such as wiki which provides the opportunity for constant feedback can significantly increase mutual understanding (Fuchs-Kittowski \& Kohler, 2002).

Furthermore, in a recent Employment Skills Survey (2006) being able to work as part of a team and well developed interpersonal skills were listed by employers among the top 10 skills/attributes sought after in university graduates. Team work has also been identified as one of the core transferable skills valued by employers in the workplace in other surveys, such as the survey conducted by the University of Dublin (Curry, Sherry \& Tunney, 2003), and a Graduate Careers Australia's (GCA) survey of employers in Australia and New Zealand (GCA, 2006).

\section{Wiki as a means of supporting collaboration}

Barkley et al. (2005: 9) list five elements needed for successful collaborative learning. One of these principles is positive interdependence, i.e., course work and assessment are designed in such a way that the success of an individual is linked to the success of the group. Wiki technology is able to support this aspect of collaborative learning not only for on campus students, but also for geographically dispersed distance students, by making it possible for individuals to contribute towards a joint assessed outcome. Another important principle is individual and group responsibility, implying that students each have a fair share of the work and that they are assessed individually. Here the advantage of using wiki technology as a platform for conducting group assessment is that it can make the quantity and quality of each group member's contribution more transparent, potentially encouraging participation and making it easier to mark group work. This would counteract some commonly known problems with group work, such as attempts by some students to dominate group work, on the one hand, and attempts of other students to get away with the least among of work possible, on the other.

The use of wikis in group projects is predicted to encourage a more equal participation from all team members, since on a wiki a record is kept of every contribution to every 
web page, when it was made and who made it, allowing the lecturer to judge both the quantity and quality of contributions by different team members. As far as the tendency of some students to dominate group work is concerned, the asynchronous nature of wiki contributions and ability to edit each other's work may allow the "quiet" student to make a significant contribution to the assessed outcomes. This asynchronous written mode of contributions also encourages students from nonEnglish speaking backgrounds to take a more active role in the project (Elgort, Marshall \& Pauleen, 2003).

In her research on the use of wikis in a distance learning graduate level course, Bold (2006) reports that the wiki tool was used to transfer the responsibility for housekeeping tasks (such as team signup) normally carried out by the faculty, over to the students. Such use of wikis can encourage students to take more control over their own learning.

Beyond the higher education context, research (Davison, 2001) on group decision support tools has investigated the use of ICT to develop more equitable collaboration between participants in business meetings. In traditional face to face meetings it is not uncommon for a small number of attendees to dominate the discussion. With group decision support tools attendees input their ideas and vote on them anonymously using a personal computer. This helps to produce more democratic decision making in meetings. Though contributions to wikis used in our study were not anonymous, individual authorship is not accentuated in wiki pages that look like one body of text. In addition, an ability to edit and comment on each other's work in an asynchronous manner takes away the pressures of a face to face meeting where participants must consider and respond to new ideas on the spot, allowing students with different learning and communication styles to contribute meaningfully to group work.

Overall, effective student participation in collaborative knowledge creation and sharing is an important learning outcome for higher education courses. For postgraduate students, the goal moves beyond this; the students should feel that they are becoming members of a professional community of enquiry (Lipman, 1991). A course wiki is a tool that has the potential to assist with modelling such communities.

Along with these potential benefits afforded by wikis, this technology requires users to adopt new approaches to reading, writing and editing. For example, a wiki has no predefined structure; wiki pages are easy to create and edit without any prior experience in writing web pages; formatting opportunities in wiki pages are very limited, resulting in wiki pages, as a rule, being very "plain" (Bold, 2006; Bryant, 2006; Engstrom \& Jewett, 2005; Fuchs-Kittowski \& Kohler, 2002; Lamb, 2004; Raman, Ryan \& Olfman, 2005).

\section{Wiki as a means of supporting knowledge construction}

Wikis are generally perceived as social software and, like other social networking software, offer new ways for students to interact with their classmates and the wider world (Bryant, 2006). The functionality of a wiki can potentially improve knowledge sharing and collaborative knowledge construction within an academic environment (Fuchs-Kittowski \& Kohler, 2002; Raman et al., 2005). One of the main advantages of wikis is that unlike standard content management systems they permit both interaction and simultaneous work on the conjoined result, thereby removing the 
boundaries between the active author and the passive user of content (Fuchs-Kittowki \& Kohler, 2002). Many studies, however, view wiki interaction in a very narrow way, as a kind of asynchronous discourse similar to that of an email exchange or a bulletin board discussion (see examples below). Bold (2006); for example, points out that the use of CoWeb tools like wikis does not prompt more discussion than threaded discussions in a content management system, like Blackboard: many students contributed only one post.

Raman et al. (2005) conducted case study research to investigate whether wiki technology was an effective tool to support knowledge sharing and creation in an academic environment. They used an open source product called TikiWiki as a knowledge management tool with a face to face postgraduate class of 20 students, and carried out in depth follow up interviews with the students. Raman et al.'s research found that most students used the wiki for between 3 to 5 hours per week; however they tended to use it in a limited way. The wiki was used mainly to follow up on the content covered in the face to face class, and only two students used it to facilitate team discussions. The wiki was mostly used as a tool to create and extract knowledge directly relevant to the class, for example summaries of recommended readings, however there was very limited use of the wiki to facilitate collaborative knowledge creation and sharing. The researchers concluded that the wiki was most useful as a tool to manage and update existing knowledge, but of limited use to collaboratively create new knowledge.

In a large school based project involving 11 teachers and nearly 400 students, Engstrom \& Jewett (2005) reported that the students were good at posting information, but not so good at sharing information or exchanging ideas. This resulted in surface rather than deep thinking. The authors concluded that in today's world, where students are digital natives (Prensky, 2001) used to an instant response, the challenge is to facilitate the use of wikis to promote deep learning (Biggs, 1987; Ramsden, 2003).

The above studies show that wikis are often perceived as a type of asynchronous communication tool, and compared with discussion boards. However, we believe this comparison is not justified. The nature of interaction in wikis is fundamentally different from that of threaded discussions; it is interaction through action. Participants in a group project wiki work together towards a common goal, i.e., not so much engaging in a discussion about concepts and their application, but actually applying what they know and have learned, and demonstrating their understanding in action. It is through the prism of this cooperative and collaborative activity that the processes of knowledge construction can materialise in a wiki environment. Of course, communication is part of this process, but it is usually accomplished indirectly, through negotiating the content and structure of a wiki, collaborative editing of information and commenting on each other's contributions. A threaded discussion board on the other hand supports communication in the form of a more traditional discourse.

There are also other functions that course wiki can perform. Raman et al. (2005), for example, propose that wikis create a body of students' work that could potentially be built on by future classes. Once a wiki has been created it will persist and can be built up as a knowledge repository. Thus, the body of knowledge may grow incorporating contributions from previous and current student cohorts. 


\section{Methodology}

The University Ethics Committee approval was obtained for the project. Data was collected using student survey questionnaires [Appendix 1] administered by the instructors to students at the end of the course. A pool of survey questions was offered to the instructors of the participating courses, so that they could select questions that they considered most relevant to their course. As a result some of the questions in the two questionnaires were different, but there was also a considerable overlap in the chosen questions. The questionnaires included both multiple choice questions and open ended comments. A five-point Likert scale (strongly agree, agree, neutral, disagree and strongly disagree) was used for the questions eliciting student perceptions.

Both courses included questions related to the group work and face to face and online collaboration modes, as well as questions related specifically to the use of the Teams LX wiki tool. In both courses the survey was anonymous, but in Course B the questionnaire was administered as an online survey, while in Course A it was administered in a lecture. Although the instructor of Course B was aware of a lower response rate generally associated with online surveys, this delivery method was chosen because the majority of students were taking this course in distance mode. Both questionnaires were conducted during the last week of the course, before students received their marks. In addition, the instructors and researcher were able to view snapshots of the collaborative process involved in the construction of the wikis at its various stages, using the history feature of the Teams LX tool. In Course B, students were also required to keep an online journal, which provided an insight into their perceptions of the collaborative processes. Instructors' feedback was collected in a debrief session straight after the end of the course.

\section{Courses participating in the study}

\section{Course A}

Course A, Information Systems and Technologies, is a core course on the Master's in Information Management (MIM) programme. The MIM is a postgraduate, postexperience professional managerial qualification that is usually taken on a part time basis. Emphasis is placed on the development of managerial skills in realistic organisational environments. The course is taught in a traditional face to face mode; students meet for two hours per week for each course, and are typically taking two courses per semester.

One of the course assignments is for small groups of students to investigate a Leading Edge Information Technology topic, for example grid computing or open source software. The students have to find articles about their topic in the academic literature and prepare a report; they also have to give a 20-minute presentation to the class. Students are randomly allocated to groups, and can choose their topic from a short list provided by the lecturer.

For the pilot, students were instructed to produce a knowledge base about their topic using a wiki. The motivation for selecting the wiki technology was twofold. The IT (Information Technology) background of Course A students is mixed; though most have practical experience of using various IT packages and programs, a significant 
minority have very little IT experience. One of the objectives of the course is to build up the skills and confidence of these less IT literate students. As wikis are not yet widely used in the business environment, it was felt that their novelty value would also keep engaged those students who were IT literate. The second reason was that wikis support individual student contributions and would allow groups to work together in a dispersed environment providing a good way for part time students to collaborate on a group project outside of contact teaching hours.

The assignment was marked using a structured marking sheet which was distributed to students with the assignment specification. As well as demonstrating knowledge of the topic students were awarded marks for the way they structured the knowledge base, and for the quality of synthesising the materials sourced from academic articles. It was important that the wiki was designed as one cohesive site, and that it showed evidence of collaboration, rather than appearing to be the work of separate individuals. Groups had an option of requesting that each member be marked individually, but none of the groups chose to do so. Thus one mark was awarded to all group members.

\section{Course B}

Course B, Advanced Reference Services, is an elective course in a Master of Library and Information Studies, a postgraduate professional program for librarians and information workers. The course is offered both by conventional face to face teaching on campus, and as a distance course supported using voice over IP conferencing. In addition, both on campus and distance students use Blackboard to download course materials and communicate through online discussion forums. Students taking this course are generally competent in the use of IT, and, through previous courses, have basic HTML skills.

A common feature of library service is to create web based resource guides that evaluate and link to online resources appropriate for the library's users. Therefore, part of the assessment for Course B is a group project to create a web based guide to online resources in a specific subject area. For this project, small groups of students are self selecting, generally based on an interest in a common topic, but also driven by geographical proximity (particularly in the case of distance students).

In previous years, the group assignment was implemented using a web server, with students using file transfer protocol (FTP) to upload files to the server over the Internet. While this approach was generally successful, the management of the group site was time consuming, and the FTP technology proved difficult for some students to use. Using a wiki to implement the web based resource guide was an opportunity to see if an easier to use technology would promote more balanced individual contributions and better collaboration. Another objective was to find out if a wiki was useful for overcoming the isolation often felt by distance students. Introducing this technology also reflected the lecturer's belief that distributed content management tools, such as wiki, are likely be part of professional practice in information work in future (e.g., Chawner \& Lewis, 2006; Frumkin, 2005).

The Web based resource guide included three components: the resource guide - a website providing links and evaluations of information resources in a specific topic; presentation of the completed guide to the class; and an online reflective journal, in which students were asked to describe the process of creating the guide, and to reflect 
on their own contribution to the project. For the first two components students received a group mark, while the journals were marked individually. The guide had to reflect the nature of the subject, and to aid access by the user.

\section{Results for Course A}

\section{The respondent population}

Out of the 17 students who took the course 16 responses were received (94\%). Most students (as expected) identified themselves as strongly computer literate; the majority used computers off campus and had used Blackboard prior to the course. The wiki was a novelty though, with $75 \%$ of students reporting that this was the first time they had used a wiki. This was an attractor for them: positive comments about using the wiki were made in the course feedback, with the students enjoying the experience of working with a new technology.

\section{The group process}

The results revealed that the majority of the students spent a significant proportion of their time (50\% or more) working individually on the assignment. A somewhat lower proportion of the time was spent in a face to face meeting mode. The least time was spent working together online, with $25 \%$ of the students not having worked online as a group at all.

\section{Attitudes to group work}

Overall, most students (88\%) thought that the group assignment provided them with a valuable learning experience. They reported operating fairly structured groups with a group leader and defined roles for all members. However only half of the students felt that all group members contributed a fair amount of work, and a quarter of the respondents felt that some group members had not done an equal share of the work.

The majority of students felt they worked well together in the face to face and online modes, but there was a slight preference for the face to face mode; indeed, groups were often seen meeting before or after the scheduled lecture. Nevertheless, $25 \%$ of the students felt that some group members had dominated face to face meetings, though for the majority of students this was not an issue. Responses were almost evenly split on whether knowledge sharing was most effectively done using wikis or in face to face meetings, but the face to face mode was clearly considered more productive $(81 \%$ in favour) as far as interaction with other team members was concerned. This confirms our earlier point that wikis may not be very effective as a communication tool.

Although the majority of students were neutral about whether they preferred individual or group work, just under half of the students $(44 \%)$ indicated a preference for working alone rather than in a group. In response to the question of whether the students felt they could have completed the assignment better on their own than working as a group, the responses were also fairly evenly split (38\% were in agreement, $44 \%$ disagreed, and the rest were neutral).

\section{Using wikis}

Two thirds of the students thought that the wiki was a good tool to collect and organise information for the assignment, and 75\% also thought it worked well as a tool to 
present the results of the group assignment. Student views on whether the use of wiki encouraged better individual participation were more split, with $44 \%$ thinking that this was the case, $19 \%$ disagreeing and $37 \%$ being uncertain.

\section{The lecturer's view}

The lecturer thought that the wiki worked well in motivating the students, because it was something new and caught their attention. Another advantage of using group wikis was that they allowed students to work on their assignment both off and on site at any time, and version control was not an issue. One major advantage according to the lecturer was that the Teams LX wiki had a detailed audit trail which was very helpful in marking the assessment, making it possible to closely scrutinise individual student contributions and also to get an overview of the proportion of work done by each student on the whole wiki site. It provided some useful "hard evidence" in the case of group disputes, as it was obvious from the low number of contributions if a group member had been "free riding".

One disadvantage, according to the lecturer, was that student pre-conceptions about wikis might have worked against their willingness to refer the academic literature. Because they were already working online, the tendency was for students to look for reference materials that also were online, but students did not always choose to refer to more sound academic online resources, such as peer reviewed journal articles or conference proceedings.

\section{Technology}

A clear majority $(88 \%)$ thought that the Teams LX wiki was easy to use. In addition, the students commented positively on the $24 / 7$ availability and the ability to store shared data. Not many students had had prior experience using a wiki, but those who had, indicated that the wiki tool used in the course was either the same or easier to use than other wikis, and overall as effective as other wikis they had used. They also liked that all group members could be involved in editing (as there were no versioning problems), that they were able to check on the progress that other group members were making, and had the facility to edit each others work.

There were also things students considered problematic. For example, some students pointed out that wikis were not a good presentation tool to use with a face to face audience, and that there was little security or protection of privacy. Though one student had commented favourably on the ease of navigation, another found it cumbersome. Other negative comments were about the limited formatting features and the slow speed of the wiki (the latter issue could have been related to the fact that the wiki was installed on a test rather than the main production environment).

One student held the view that a wiki was not an appropriate vehicle for an academic assignment, as the whole ethos of a wiki "is about freedom of expression and the ability to link anywhere and make any kind of comment, which doesn't fit easily with the conventions of an academic assignment". Thus wikis are perceived as social software, and as such carrying certain assumptions about their application and modes of use. 


\section{Results for Course B}

\section{The respondent population}

In Course B, an online questionnaire was delivered to the students using the Blackboard anonymous survey tool, resulting in the response rate of $66 \%$ of all enrolled students. The respondents were eight (out of twelve) on campus students, and ten (out of fifteen) students who took the course by distance. So the response rate was not affected by the course delivery mode. This response rate was fairly good for a non-compulsory electronic questionnaire, which are known to attract lower response rates than paper questionnaires (e.g. Sheehan, 2001). A clear majority of the students were confident computer users $(83 \%)$, with the distance students demonstrating a particularly high level of confidence.

\section{The group process}

For obvious reasons, a large proportion of the distance students (80\%) did not participate in face to face group work. All the on campus students, on the other hand, did some face to face group work, with a quarter of these students spending more than $75 \%$ of their time working together in a face to face mode. However, similar to Course A, the preferred work mode for this assignment was "working alone" (for example, selecting materials, developing wiki pages or writing entries in the online journal), with a clear majority of students spending $50 \%$ or more of their overall time working alone. Online group work constituted about a quarter of the overall time spent by the students on the assignment for both the on campus and distance students, but for the on campus students this was accompanied by face to face group work. This indicates that the availability of online collaboration tools, such as wikis, is not enough by itself to overcome the isolation of distance students and encourage them to work collaboratively together, as a group. On the other hand, some of the geographically dispersed groups were inventive in using technology to communicate, in particular, making use of the online conferencing system to have audio discussions.

\section{Attitudes to group work}

Overall, students were very positive about the contribution of the group assignment to their learning: $94 \%$ of students agreed or strongly agreed that this assignment provided them with a valuable learning experience, with only one person strongly disagreeing. They also thought that they worked together well, in both face to face and online groups. The majority of students $(70 \%)$ agreed that all group members did their fair share of work (with 12\% being neutral and 18\% disagreeing), which was a better result than that in Course A, where only half of the students agreed with this statement.

It was not clear from the responses whether students felt that group members had had clearly defined roles. The distance and on campus students' approach to group leadership was quite different: $60 \%$ of the distance students disagreed with the statement "our group had a leader/leaders", but no on campus students disagreed with this statement. This may indicate that distance student groups were less wellorganised, or that they were more consensus driven.

Similar to Course A, the students were "tripolar" on whether they could have done the assignment better on their own, but the largest number (44\%) disagreed with this statement. Student comments show that group interactions enhanced the project, for 
example, a student commented positively on "[b]eing able to leverage off other people's ideas as work progressed." However, 33\% of students thought that they would have done better on their own, with the remaining students being neutral. A third of the students $(33 \%)$ also indicated that they preferred working alone rather than in groups, with three students being strongly against group work.

\section{Using wikis}

A clear majority $(77 \%)$ agreed that using wikis encouraged better individual participation in the group project. Furthermore, the same percentage of students thought that using wikis had advantages over the face to face mode in doing group work. In addition, $59 \%$ of students thought that this was a good way to get to know other members of the class. This applied equally to the distance and on campus students, even though it had been anticipated that the social benefits would be more significant for distance students.

In their comments students also reported that some groups had set up a separate wiki area for administrative purposes, such as meetings' notes and keeping records of group decisions. This use of wikis is well-documented in the literature (e.g. Lamb, 2004).

\section{The lecturer's view}

From the lecturer's point of view, the use of wikis for the resource guide task helped students in achieving the course objectives, and there was little discernable difference between the distance and on campus groups in their success in achieving the objectives of the task. One of the indicators of the effectiveness of the wiki and other technologies used in the course was that the average marks for the group project were very similar for the on campus $(71 \%)$ and distance students $(72 \%)$, indicating that students had not been disadvantaged by lack of physical contact. According to the lecturer, because the resource guide assignment was based in cyberspace, virtual group work was particularly appropriate. Also, the task given to students was relatively easy to compartmentalise between different individuals. On the other hand, the lecturer thought that a wiki based approach might not be appropriate for other types of group work that require more personal interaction.

The lecturer also thought that using wikis had an advantage over the previous form of this assignment, which required students to use HTML editors to create and edit web pages and then upload them to the central server, because students could concentrate on the core objectives of the course, i.e., structuring and evaluating information, rather than on the technical issues of constructing a website. Freeing the instructor from the need to provide support on the FTP uploading of files and HTML tagging issues was also an advantage. However, using wikis meant that students didn't reinforce these technical skills in the way that had been done in the past. Arguably though, in the workplace, students are more likely to be building and maintaining websites with a content management system that would be similar to a wiki, rather than writing raw HTML and using the FTP technology (Godwin, 2006). Thus the wiki task is probably closer to the "real world" than the exercise of HTML and FTP skills.

Overall, the lecturer thought that while working in virtual groups had been a challenge to many of the students, it reflected the realities of a modern working environment. 


\section{Technology}

Regarding the technology, the majority of the students (80\%) felt that the wiki worked well for creating an online resources guide. The wiki was judged easy to use by $70 \%$ of the students. This was also reflected in the comments:

Wiki was great - easy to use and update. We could see immediately what had been done.

While I have a basic understanding of HTML ... great not having to deal too much with the 'technical' side.

However one student would have liked to have more exposure to web skills, noting that s/he "learned more about working in groups than about creating a web resource". Although using wikis did not require knowledge of HTML, users could however switch to the HTML mode if they wished, and some basic HTML knowledge was often useful, for example when pasting text from a word processed document into wiki pages, and removing unwanted coding.

Particularly for distance students, the ability to work on the project remotely was perceived as useful. One student commented, "[g]reat being able to work on the wiki from different locations - as distance learning student this was fantastic". Several groups discovered the advantage of shared "templates" to create a common appearance to the group site.

Students also mentioned a number of technical issues (e.g. wiki pages were often locked for a long time after they had been edited; the list of wiki pages used by students to navigate the site was slow to be generated; editing options were limited). The majority of these issues are limitations associated with the early version of the wiki software and have been fixed in the later versions of the software.

\section{Discussion and recommendations}

\section{Levels of cognitive processing}

Both the examination of the wikis produced by the students and their responses to the question of whether knowledge sharing was enhanced by using wikis appear to indicate that when students used wikis for team work they were more likely to engage in activities associated with the application of knowledge and possibly synthesis, than in the processes associated with evaluation (Anderson \& Krathwohl, 2001). Since this seems to be the case not only in our research, but also in the studies reviewed earlier, it may be suggested that the requirement to use a wiki in group work does not in itself communicate high expectations. Therefore in order to encourage students to engage critically with the materials and sources they use in their wiki based work, group tasks need to be designed to facilitate critical judgement and assessment criteria need to foreground analysis and evaluation of information.

\section{Group work}

In relation to group work, it was a concern that, while most students in both courses agreed that doing the group assignment was a valuable learning experience, significant numbers felt they could have done the assignment better on their own. This 
raises the question of whether the ability to work in a group should be emphasised more strongly in the course objectives and design.

Furthermore, even the most cursory observation of the final wikis gave a good insight into how the group process had worked. Some groups had produced carefully planned, beautifully coordinated sites which indicated that the students had worked well as a group, other wikis were clearly the work of separate individuals each using their own approach. This demonstrates that using a wiki is no guarantee that individuals will work together as a group. Therefore, if effective team work and collaboration are the desired learning outcomes, then scaffolding may be required to help students prepare for group assessment. This can be done by modelling good practice using 'mini wiki-tasks' prior to the main group assessment.

\section{Quality of student contributions}

Another lesson learned was that using web based tools such as wikis may be interpreted by students as requiring less academic rigour. This indicates that it is crucial to ensure that students know how to access the desirable sources of information, and to put more emphasis on the quality of sources in the assessment criteria. It is also important to emphasise the genre in which students are working, i.e., academic writing. Students are usually familiar with the differences between writing a personal letter, an article to a student magazine and a university essay, because, as a rule, they are taught about these different genres of writing at school. When working in a wiki, these distinctions can easily become blurred because wikis are commonly perceived as social software, informal and imprecise. Therefore when wikis are used as part of a tertiary course of study, it is particularly important to emphasise the academic nature of student contributions.

\section{Marking students' work in a wiki}

An interesting question raised by both lecturers was whether the marking process for a project or assignment done using a wiki should also be incorporated into the wiki (for example by adding annotations to the pages in the assessed wiki). In the present study this wasn't done for two reasons:

- Changing the wiki by the lecturer ran the risk of lessening the integrity of students' work, as it might have become unclear what had actually been submitted.

- In a non-linear document like a wiki, it could be difficult for a student to find and follow all comments relating to their individual work, resulting in students missing out on feedback.

Whether the lecturers' feedback can be effectively embedded in the wiki appears to depend on the availability of the 'right' technological solution. A useful enhancement to a wiki software designed for educational use, for example, would be the ability of the lecturer to annotate work in a way that did not change the wiki, and to provide student tools for browsing these annotations. In the Teams LX wiki, it is possible to leave comments associated with specific wiki pages that are separate from the wiki pages, but these comments cannot be hyperlinked to the parts of the pages to which they refer. The Teams $L X$ wiki also allows the setting of a date after which the wiki can no longer be further edited by the students, which emulates a traditional submission. On the other hand, it may be beneficial to allow students to act on the feedback even 
after the assignments have been marked, if the wiki is to have a life outside the course (for example, if it is used as a resource for the following courses or is later published on the web). We believe that the whole issue of marking wikis deserves special attention, as to our knowledge no research on the effectiveness of different approaches to marking wikis has been conducted so far.

\section{Conclusion}

In this project we have considered students' and lecturers' views on using wikis in the context of course group work. The overall results are encouraging, indicating that both the students and the instructors saw value in using wikis as a collaboration tool. From the students' perspective, wikis encouraged better individual participation and were a good tool for collecting and organising information for group projects. From the lecturers' perspective, the use of the Teams LX wikis contributed to the ease of managing and marking student work in a group project.

However, the use of wikis was not enough to counteract some students' preference for working alone rather than as part of a team. In addition, our prediction that distance students may choose to use wikis in order to feel less isolated was generally borne out, although on campus students also felt that it was a good way to get to know other members of the class. Distance students also looked for other ways of compensating for the lack of face to face contact, such as self initiated audio conferencing sessions.

\section{References}

Anderson, L. W. \& Krathwohl, D. R. (2001). A taxonomy for learning, teaching, and assessing: A revision of Bloom's taxonomy of educational objectives. New York: Longman.

Augar, N., Raitman, R. \& Zhou, W. (2004). Teaching and learning online with wikis. In Beyond the Comfort Zone: Proceedings ASCILITE 2004 (pp.95-104). Perth, WA.

http: / / www.ascilite.org.au/conferences/perth04/procs/augar.html

Barkley, E. F., Cross, K. P. \& Major, C. H. (2005). Collaborative learning techniques: A handbook for college faculty. San Francisco; Jossey-Bass Publishers.

Biggs, J. B. (1987). Student approaches to learning and studying. Melbourne: Australian Council for Educational Research.

Bold, M. (2006). Use of wikis in graduate course work. Journal of Interactive Learning Research, $17(1), 5-14$.

Bower, M., Woo, K., Roberts, M. \& Watters, P.A. (2006). Wiki pedagogy - A tale of two wikis. Paper presented at the 7th International Conference on Information Technology Based Higher Education and Training (ITHET 06), Sydney, Australia.

Bryant, T. (2006). Social software in academia. EDUCAUSE Quarterly, 2, 61-64. http:/ / www.educause.edu/ir/library/pdf/eqm0627.pdf

Chickering, A. W. \& Gamson, Z. F. (1987). Seven principles for good practice in undergraduate education. AAHE Bulletin, 39(7), 3-7. [verified 3 Feb 2008] http: / / learningcommons.evergreen.edu/pdf/ fall1987.pdf 
Chawner, B. \& Lewis, P. H. (2006). WikiWikiWebs: New ways to communicate in a web environment. Information Technology and Libraries, 5(1), 33-43. [verified 3 Feb 2008] http:/ / www.ala.org/ala/ lita/litapublications/ital/252006/2501mar/communications.cfm

Choy, S. O. \& Ng, K. C. (2007). Implementing wiki software for supplementing online learning. Australasian Journal of Educational Technology, 23(2), 209-226. http:/ / www.ascilite.org.au/ajet/ajet23/ choy.html

Conole, G. \& Dyke, M. (2004). What are the affordances of information and communication technologies? ALT-J: Research in Learning Technology, 12(2), 113-124.

Curry, P., Sherry, R. \& Tunney, O. (2003). What transferable skills do employers look for in third-level graduates? Dublin: University of Dublin Trinity College. [viewed June 2007]. http:/ / www.skillsproject.ie/ downloads / pdfs/Summary\%20Employer\%20Report.pdf

Davison, R. (2001). GSS and action research in the Hong Kong police. Information Technology $\mathcal{E}$ People, 14(1), 60-77.

Duffy, T. M. \& Jonassen, D. H. (1992). Constructivism and the technology of instruction: A conversation. Hillsdale, NJ: Lawrence Erlbaum.

Employment Skills Survey: December 2006 (2006). Victoria University of Wellington [viewed Feb 2007]. http:// www.victoria.ac.nz/st_services/careers/resources/employment_skills_survey.aspx

Elgort, I. (2007). Using wikis as a learning tool in higher education. In ICT: Providing choices for learners and learning. Proceedings ascilite Singapore 2007.

http:/ / www.ascilite.org.au/conferences/singapore07/ procs/elgort.pdf

Elgort, I., Marshall, S. \& Pauleen, D. (2003). NESB student attitudes to an ICT-supported team project. In Interact, Integrate, Impact: Proceedings ASCILITE 2003. Adelaide, SA. http: / / ascilite.org.au/conferences/adelaide03/docs/pdf/601.pdf

Engstrom, M. E. \& Jewett, D. (2005). Collaborative learning the wiki way. TechTrends, 49(6), 12 $15,68$.

Frumkin, J. (2005). The wiki and the digital library. OCLC Systems \& Services, 21(1), 18-22.

Fuchs-Kittowski, F. \& Kohler, A. (2002). Knowledge creating communities in the context of work processes. SIGGROUP Bulletin, 23(3), 8-13.

Godwin, P. (2006). Information literacy in the age of amateurs. How Google and Web 2.0 affect librarians' support of information literacy. ITALICS, 5(4). [viewed July 2007]. http:// www.ics.heacademy.ac.uk/italics/vol5iss4/godwin.pdf

Grierson, H., Nicol, D., Littlejohn, A. \& Wodehouse, A. (2004). Structuring and sharing information resources to support concept development and design learning. Paper presented at the Network Learning Conference, Exeter, UK, pp. 572-579. [verified 8 Feb 2008] http: / / www.networkedlearningconference.org.uk/past/nlc2004/proceedings/ individual_papers/grierson_et_al.htm

GCA (2006). Graduate Outlook 2006: A snapshot. [viewed June 2007]. http: / / www.graduatecareers.com.au/ content/view / full/ 2675

Hargadon, A. (2003). How breakthroughs happen: The surprising truth about how companies innovate. Boston, MA: Harvard Business School Press.

Harel, I. \& Papert, S. (1991). Constructionism. Norwood, NJ: Ablex. 
Lamb, B. (2004). Wide open spaces: Wikis ready or not. EDUCAUSE Review, 39(5), 36-48.

http: / / www.educause.edu/ir/library/pdf/ERM0452.pdf

Learning Objects Campus Pack (2008). Learning Objects, Inc. http:/ / www.learningobjects.com/

Lipman, M. (1991). Thinking in education. New York: Cambridge University Press.

Millis, B. J. \& Cottell, P. G. (1998). Cooperative learning for higher education faculty. Phoenix, AZ: Oryx Press.

Prensky, M. (2001). Digital natives, digital immigrants. On the Horizon, 9(5), 1-6. [viewed April 2003]. http: / / www.marcprensky.com/ writing/Prensky\%20-

$\%$ 20Digital $\%$ 20Natives, \%20Digital\%20Immigrants \%20-\%20Part1.pdf

Raman, M., Ryan, T. \& Olfman, L. (2005). Designing knowledge management systems for teaching and learning with wiki technology. Journal of Information Systems Education, 16, 311320 .

Sheehan, K. (2001). E-mail survey response rates: A review. Journal of Computer Mediated Communication, 6(2). [verified 3 Feb 2008] http:/ / jcmc.indiana.edu/vol6/issue2/sheehan.html

Wikipedia (2008). http: / / www.wikipedia.org/

\section{Appendix 1: Survey}

Appendix 1 is available in the file http:/ / www.ascilite.org.au/ajet/ajet24/elgort-appendix.pdf

Note that the lecturers participating in this project were given an option of not using all of the questions included in this questionnaire, but selecting the ones that were more relevant for their course. Therefore, even though there was a considerable overlap in the final set of questions selected for individual courses, some questions were used in one course but not the other, and some were not used at all.

Irina Elgort, University Teaching Development Centre

Alastair G Smith and Janet Toland, School of Information Management

Victoria University of Wellington, PO Box 600, Wellington 6140, New Zealand

Email: irina.elgort@vuw.ac.nz, alastair.smith@vuw.ac.nz, janet.toland@vuw.ac.nz 